Article

\title{
Drivers of Growth in the Travel and Tourism Industry in Malaysia: A Geweke Causality Analysis
}

\author{
Tan Khee Giap *, Sasidaran Gopalan and Ye Ye
}

Asia Competitiveness Institute, Lee Kuan Yew School of Public Policy, National University of Singapore, Singapore 259770, Singapore; sppsdg@nus.edu.sg (S.G.); yeyechristine@163.com (Y.Y.)

* Correspondence: spptkg@nus.edu.sg; Tel.: +65-6516-3803

Academic Editor: David O. Dapice

Received: 2 November 2015; Accepted: 23 February 2016; Published: 26 February 2016

\begin{abstract}
The travel and tourism industry has been growing in importance for several developing countries. It has not only generated considerable foreign exchange revenues but has also contributed to the overall output and socio-economic development of these countries. Within the Asia and Pacific region, data for 2014 indicates that Malaysia was ranked very highly at no. 26 out of the 184 countries in the world in terms of the relative importance of the contribution of the travel and tourism industry to its national output. In this light, this paper aims to undertake an empirical examination of the factors driving international tourist arrivals into Malaysia. The paper attempts to identify the causal determinants of the growth of the travel and tourism industry, using quarterly data from 2000 to 2012, under a Geweke causality framework. The empirical results suggest Malaysia's government expenditures on tourism promotion as well as infrastructure investments such as enhancing airport facilities are causal and significant determinants of growth in the travel and tourism industry.
\end{abstract}

Keywords: Geweke causality; economic growth; travel and tourism; Malaysia; competitiveness

JEL Classification: E2; O40; Z3

\section{Introduction and Motivation}

Travel and tourism (T\&T) play a pivotal role in the global economy. As countries increasingly open up their borders to join the wave of global integration, the development of the T\&T industry has become a source of substantial foreign exchange revenues for several economies. Furthermore, countries have increasingly witnessed the contribution of the T\&T industry to their overall socio-economic development through its employment creation potential. Policies intended to boost the local economy through the development of the T\&T industry create both direct and indirect employment in addition to facilitating backward and forward linkages with other allied industries. Considering that focusing on the development of the domestic tourism industry helps countries achieve competitiveness in the global markets, significant investments in the development and promotion of the T\&T industry remains a policy priority globally (Gopalan, 2013 [1]).

A prominent feature of the T\&T industry is its potential to create backward and forward linkages that are not only strong but also diverse. Further, such linkages generate broader multiplier effects through the economy leading to broad-based economic benefits including higher employment opportunities both at the national and local levels (UNCTAD, 2013 [2]). The fundamental reason why the T\&T industry has the potential to generate such strong backward and forward linkages can be understood from the diversity of allied sectors that are part of the "tourism value chain." As UNCTAD $(2013,[2]$ p. 7) notes, promotion of tourism, for instance, requires "the construction and operation of 
quality hotels, restaurants and other related facilities through backward linkages." Similarly, a range of forward linkages can be generated through "sectors supplying a variety of services consumed by tourists that include financial, telecommunications, retail, recreational, cultural, personal, hospitality, security and health services" (UNCTAD, 2013, [2] p. 7). Thus, the resultant expansion of the T\&T industry would pave the way for increased demand for the construction of tourism facilities covering the whole gamut of allied services, which creates multiplier effects along the value chain that benefits the entire economy.

This appears to be the context in which most of the related academic literature on the T\&T industry explains its economic significance, in particular, focusing on the potential impact of growth of the $\mathrm{T} \& \mathrm{~T}$ industry on poverty alleviation in emerging and developing economies. For instance, a recent comprehensive survey study by the Overseas Development Institute (ODI, 2007 [3]) offers a useful conceptual framework to illustrate this link between tourism and poverty alleviation. As noted by ODI (2007 [3]), there are three major "pathways" — "direct", "indirect" and "dynamic"—through which tourism can impact poverty reduction:

The direct effects pertain to the incomes that are generated from tourism jobs. Estimates from United Nations World Tourism Organization (UNWTO) suggest that tourism's total contribution to global employment in 2013 between 6 and 7 percent of the overall number of jobs in the world. The indirect channel relates to the tourism value chain where the earnings are generated from allied sectors such as food or transportation industries. Studies suggest that inter-sectoral impacts are substantial and make up about 60 to 70 percent of earnings in the industry in developing economies, in addition to the direct effects of tourism (Ashley et al. 2007 [4]). Finally, the dynamic channel spans a wide spectrum as the development of the tourism industry in an economy can enhance the livelihoods of local households, improve the business environment for small enterprises and also ease the infrastructural bottlenecks in an economy, all of which can contribute to poverty reduction through growth.

The growing significance of tourism in the world can also be tracked by various factors including the growth in international tourist arrivals, the consequent growth in tourism revenues, its total contribution to foreign exchange earnings as well as gross output in the particular country. For instance, the T\&T industry globally in 2014 generated US $\$ 7.6$ trillion which translates into 10 percent of global GDP and 277 million jobs (1 in 11 jobs) for the global economy in 2014 (UNWTO, 2015 [5]). Further, the total number of international tourist arrivals globally was over 1 billion and, tourists from emerging economies represented almost half of these international arrivals.

Among the various regions in the world, Europe and the Asia-Pacific regions have consistently stood out as the world's most preferred destinations, with both regions making up about 60 percent (on average) of global tourist arrivals during the last decade or so. Zooming in on the Asia and Pacific region, as per the statistics produced by the World Travel and Tourism Council (WTTC), in 2014, Malaysia was ranked no. 26 out of the 184 countries in the world in terms of the relative importance of the contribution of T\&T to the country's output in 2014 (WTTC, 2015 [6]).

The T\&T industry in Malaysia has undergone tremendous growth and development since 2000. In 2014, it represented about 6 percent of total direct employment and about 14 percent of indirect employment, underlining its importance as a crucial engine and source of growth for the country (WTTC $[7,8]$ ). In terms of its contribution to the output of the economy, the T\&T industry directly contributed about 6 percent and indirectly represented over 15 percent of the Malaysia's GDP.

Inbound tourism as a service traded across borders has emerged as one of the world's important trading categories, with tourism exports accounting for as much as 30 percent of the total exports of commercial services in the world. Visitor exports, which refer to expenditures by foreign visitors, stood at about 9 percent as a share of total exports in 2014, which in local currency terms translated to about MYR 74.0 billion. The ability of the tourism industry to address the current account imbalances of a country is also widely recognized in the literature, and there are a number of studies that examine the importance of tourism through its implications for the balance of payments, especially in developing countries (for example, see Malik et al. 2010 [9]; Thano, 2015 [10]). 
In examining Malaysia's government policies directed towards the T\&T industry in recent years, the government in its New Economic Model (NEM) 2010 and 10th Malaysia Plan identified and reiterated the importance of the T\&T industry as both a National Key Economic Area (NKEA) and Strategic Reform Initiative (SRI) industry (National Economic Advisory Council, 2010 [11,12]; Prime Minister's Department Economic Planning Unit, 2010 [13]). Under these overarching national development plans, which has identified the industry as an 'economic sweet spot', the government has put forward aspirational plans that include bolstering the importance of eco-tourism, the need to develop urban tourism, tourism clusters, new tourism products, and to continue to invest in the industry and infrastructure (National Economic Advisory Council, 2010 [11,12]; Prime Minister's Department Economic Planning Unit, 2010 [13]). These efforts to develop the domestic tourism infrastructure are expected to enhance the country's competitiveness relative to other neighboring countries in the region which could make Malaysia a more attractive tourist destination in the region. With the establishment of an Association of Southeast Asian Nations (ASEAN) Economic Community (AEC) in December 2015, it is imperative that Malaysia continues to focus and develop plans to bolster its T\&T industry in order to leverage its strengths and benefit from such regional integration attempts.

In a speech dated 27 August 2015 [14], Datuk Seri Najib Razak, the Prime Minister of Malaysia was quoted as saying:

"Our renowned Malaysian hospitality and culture of service, our rich national heritage, our cultural diversity and of course, now more than ever, the value for money that foreign tourists will experience in Malaysia compared with many other destinations because of the exchange rates. All of these are huge selling points that need to be amplified and communicated across all channels to drive up tourism numbers."

As policy efforts continue to boost the T\&T industry in Malaysia, the paper is interested in empirically understanding the causal factors that drive the growth of the T\&T industry. Specifically, the paper attempts to provide an empirical explanation for the sources of international tourist arrivals in Malaysia by identifying the key causal determinants of the growth of the T\&T industry. To do this, the paper employs a novel empirical approach, the Geweke causality analysis, which helps us understand and measure the linear dependence and feedback between multiple time series variables. To that effect, we perform both a bi-variate as well as multi-variate causality analysis.

The remainder of the paper is organized as follows. Section 2 will provide a brief overview of the related literature, a backgrounder on the role and policy relevance of T\&T industry in Malaysia as well a summary of the various national initiatives that have been taken to promote the industry. The discussion in this section will thus form the basis of developing empirically testable hypotheses to identify the causal drivers of growth of the T\&T industry. We present the empirical methodology and data employed in the paper in Section 3. Section 4 discusses the empirical findings. Section 5 concludes with a discussion of the policy implications for Malaysia.

\section{Background and Hypothesis}

\subsection{Background}

Malaysia has a long history of promoting the T\&T industry and the government has played a very active role in the process by adopting and formulating several laws providing the appropriate institutional and legal framework to ensure sustainable tourism.

Though Malaysia's tourism efforts go back to the 1970s, the fact that the Malaysian economy was largely an exporter of primary commodities in the 1970s, the tourism industry was rather underdeveloped till then. With the establishment of the Tourism Development Corporation of Malaysia (TDC) in 1972, the country took a major step in the right direction to make TDC the official development authority to promote tourism and travel. However, as noted by Mosbah and Al Khuja (2014) [15], the relatively modest performance of TDC to exploit the potential of the tourism sector left Malaysia a 
largely unexplored and unknown destination for tourism in the Southeast Asian region relative to other "touristy" places such as Thailand or Indonesia.

The tipping point in Malaysia's history pertaining to the tourism industry took place in the early 1980s when there was a global tourism boom which coincided with the collapse of primary commodity prices. This paved the way for Malaysian policy makers to recognize the immense potential of the tourism sector as a tool to foster economic and social development, and in promoting greater national as well as regional integration (Mosbah and Al Khuja, 2014 [15]; Nanthakumar et al., 2007 [16]).

The country has started taking an active interest in the development of the tourism sector since then and it was best captured by the drafting and enacting of five year plans that placed the promotion of tourism and travel industry as a policy priority. These five year plans were also concomitantly supplemented with a series of policy initiatives such as the National Tourism Policy (NTP) that was enacted in 1992, the National Ecotourism Plan (NEP) in 1996 and the most recent being Malaysian Tourism Transformation Programme (MTTP) in 2010. All these policy initiatives were meant to tap into the unexploited and unexplored endowments as well as the potential that the home grown tourism and allied industries possess, which will provide a fillip to greater and sustained economic growth.

In light of all the policy discussions in Malaysia about the need for the country to develop a robust and strong services sector-which would in turn facilitate the country's transition from a middle-income status to high-income status-the government launched the Economic Transformation Programme (ETP) in 2010. One of the integral parts of this initiative pertains to the tourism sector. The T\&T industry very broadly has been explicitly recognized as one of the national key economic areas (NKEAs) able to contribute to this economic transformation. Hence, the Malaysia Tourism Transformation Programme (MTTP) was formulated to tap the growth potential of the tourism sector. MTTP aims to attract 36 million international tourists with MYR168 billion as revenues in 2020, which is thrice the amount of its present foreign exchange earnings (Ministry of Tourism, 2013 [17]). The MTTP also aims to engage in capacity building domestically so as to enhance business tourism.

Furthermore, a report published by Economic Transformation Programme (ETP) on tourism in 2012 reveals that there will be renewed focus on alleviating domestic capacity constraints in infrastructure by channeling more government expenditures to enhance the quality of tourism related infrastructure. In addition, the report points out that the priority of the country moving forward would be to project Malaysia as a global biodiversity hub by developing eco-nature resorts, as well as creating dedicated entertainment zones and improving the quantity and quality of hotels which will establish Malaysia as a leading destination for business tourism.

\subsection{Theory and Hypotheses}

There is extensive literature dating back to the 1990s which has investigated the determinants of tourism demand (See Crouch, 1994 [18]; Lim, 1997 [19]; Sheldon, 1993 [20] for comprehensive literature reviews). The literature points out that the specific variables that have been identified as plausible determinants of tourism demand in any country are real per capita income of the host countries, the (effective) exchange rate and relative prices prevailing in the host country as well as the quality of tourism infrastructure (Sheldon, 1993 [20]; Nanthakumar et al., 2007 [16]).

These variables are generally thought to be significant in explaining tourism demand for various countries. For the case of Turkey for instance, one of the early studies on tourism demand by Uysal and Crompton (1984) [21] shows that real per capita income in the host countries, relative exchange rates, transportation costs and promotional expenses drive international tourist arrivals. In similar vein, Onder et al. (2009) [22] also found that the most significant variables explaining international tourist arrivals in Turkey were real exchange rates, per capita GDP of host as well as home countries and quality of transportation.

It is interesting how there is a clear convergence of the choice of explanatory variables and the results in various country studies trying to investigate the drivers of tourism demand are quite similar. 
As an illustration, a study by Song et al. (2003) [23] for Hong Kong finds that the costs of tourism in the destination country contribute significantly to the demand for tourism in Hong Kong.

In a more recent paper, Culiuc (2014) [24] estimated the impact of both supply- and demand-side determinants of tourism to find that tourism flows respond strongly to changes in the destination country's real exchange rate. The paper also finds that tourism in smaller island countries is less sensitive to changes in the country's real exchange rate, although more sensitive to the quality of infrastructure and connectivity, specifically the introduction and removal of direct flights.

Beyond economics, tourism policy that is designed to market the distinctiveness of local traditions and culture can pave the way for better cultural exchanges between countries which can in turn foster bilateral relations between countries. The literature also points out that since tourism, by its very nature, involves and requires inter-country cooperation on many fronts, tourism policy assumes significance in shaping a country's engagement with the rest of the world (Prideaux, 2005 [25]).

The foregoing discussion leaves us with a broad idea about the variables highlighted in the literature as determinants of tourism demand. However, we go beyond just the related literature and also take a cue from the thrust of the various national policy initiatives the Malaysian government has taken in the past to identify a set of variables that could possibly be driving growth of international tourist arrivals in Malaysia.

To that end, we empirically try and understand the casual factors that affect the growth of T\&T industry in Malaysia, moving forward. We do this by employing a novel empirical methodology - the Geweke causality analysis—-to specifically analyze what factors, ranging from economic to infrastructure to environmental indicators, have a significant causal impact on the growth of the industry.

This paper sets the International Tourism Arrivals (ITA) as the dependent variable, which has been identified by the T\&T literature as one of the most appropriate variables for analyzing the industry (Lim, 1997 [19]). The following hypotheses will be tested: government policy, increased purchasing power for international tourists, improvements in the environment and infrastructure, and safety and security measures are the causal factors driving the growth of ITA into Malaysia.

The independent and control variables that we propose to include in the model can be divided into several categories. The first set of variables fall under government policy, which includes government expenditure and capital investment on the T\&T industry. The second category includes purchasing power related indicators encompassing the nominal exchange rate of the Malaysian Ringgit (MYR) to the United States Dollar (USD) and the consumer price index (CPI). The third set of variables pertains to environmental and infrastructure indicators which include airport facilities, air quality and internet users. The fourth set of indicators concern safety and security measures, which include public security and safety as well as religious unrest indicators.

By analyzing the relationship and causality between the dependent and independent variables using quarterly time series data ranging over a decade from about 2000 to 2012, the empirical results are meant to better inform and possibly propose new public policies to ensure the growth of the Malaysian T\&T sector and the Malaysian economy.

\section{Methodology and Data}

This section proceeds by discussing the methodology employed in the empirical research. The methodology presented here begins by describing the two methods used in the selection of explanatory variables. First pertains to the utilization of stepwise regression in the selection of the "best" set of explanatory variables. Second is the use of factor analysis in the construction of the different policy environments. Finally, the paper explains the Geweke causality analysis, which is applied in the paper to understand the causal factors driving the Malaysian T\&T industry. 


\subsection{Methodology}

In examining the data and choosing the "best" set of explanatory variables for the Geweke causality analysis, the paper utilizes a stepwise regression (forward selection). We first proceed by introducing one explanatory variable one at a time, and the decision to keep or drop a variable will be based on their contribution to the variance due to regression, based on the $F$ test (Gujarati, 2004 [26]). Following the application of stepwise regression and the selection of explanatory variables, we then proceed to conduct the Geweke causality analysis.

Prior to the description of Geweke causality analysis, a brief note on the variable selection through factor analysis is in order. Factor analysis consists of an "array of structure-analyzing procedures used to identify the interrelationships among a large set of observed variables and then, through data reduction, to group a smaller set of these variables into dimensions or factors that have common characteristics" (Pett, Lackey and Sullivan, 2003, [27] p. 4). In this paper, we adopt a principle component analysis method for factor analysis.

The causality and linear feedback between two linear systems are defined in Granger (1963 [28]; 1969 [29]) and Sims (1972) [30] provides complementary tests for the existence of unidirectional causality. Although the determinants of single economic variable are likely to be multidimensional, most applications found in the literature are focused on the bivariate cases. Geweke (1982) [31] developed the concept further by including the instantaneous (two-way) linear feedback between multiple time series, i.e., $F_{X, Y}=F_{X \rightarrow Y}+F_{Y \rightarrow X}+F_{X \cdot Y}$, which indicates that the measure of linear dependence, $F_{X, Y}$ is the sum of the measure of linear feedback from the first series to the second, $F_{X \rightarrow Y}$, linear feedback from the second to the first, $F_{Y \rightarrow X}$ and instantaneous linear feedback, $F_{X \cdot Y}$. The measures are non-negative, and zero only when feedback (causality) of the relevant type is absent.

The unidirectional causality analysis that is popularly employed in the literature does not investigate the degree of dependence or the extent of various kinds of feedback between different time series variables (Calderón \& Liu, 2003 [32]). However, the method suggested by Geweke (1982) [31] overcame this problem and helps to measure the linear dependence and feedback between multiple time series variables. In essence, the linear dependence is defined as "the sum of the measure of linear feedback from the first series to the second, linear feedback from the second to the first and instantaneous linear feedback" (Geweke, 1982 [31]). The direction of causality and the interplay of the variables can be examined in a more detailed manner with a reduced form quantitative framework under the Geweke causality analysis.

The multivariate causality test proposed by Geweke (1982) [31] is a test between two vectors of the variables. The equivalence of linear dependence measures as proved in one of the theorems in Geweke (1982) [31] provides us with an elegant way to conduct the multivariate test, which is as convenient as bivariate tests. Like Granger (1969) [29], Sims (1972) [30] and Geweke (1982) [31], we focus on wide-sense stationary and purely nondeterministic time series $X=\left\{x_{t}, t\right.$ real $\}$. By wide-sense stationary, we mean that we infer that the mean of $x_{t}$ exists and is independent of $t$, and for all $t$ and $s, \operatorname{cov}\left(x_{t}, x_{t+s}\right)$ exists and depends on $s$ but not on $t$. By being purely nondeterministic, we mean it presumes that the correlation of $x_{t+p}$ and $x_{t}$ vanishes as $p$ increases.

The idea of causality between multiple time series $X$ and $Y$ can be summarized as follows:

$$
F_{X, Y}=F_{X \rightarrow Y}+F_{Y \rightarrow X}+F_{X \cdot Y}
$$

A non-deterministic and stationary multiple time series can be considered as follows:

$$
Z_{t}=\sum_{s=1}^{\infty} B_{S} Z_{t-s}+\varepsilon_{t}
$$

where $\varepsilon_{t}$ is white noise and $Z_{t}$ can be partitioned into $k \times 1$ and $l \times 1$ subvectors $X_{t}$ and $Y_{t}$. 
Geweke (1982) [31] shows a canonical form for the wide sense stationary time series $Z_{t}=\left(X_{t}, Y_{t}\right)$ is of the form:

$$
\begin{array}{cc}
X_{t}=\sum_{s=1}^{\infty} E_{1 s} X_{t-s}+\mathrm{u}_{1 t} & \operatorname{var}\left(\mathrm{u}_{1 t}\right)=\sum_{1} \\
X_{t}=\sum_{s=1}^{\infty} E_{2 s} X_{t-s}+\sum_{s=1}^{\infty} F_{2 s} Y_{t-s}+\mathrm{u}_{2 t} & \operatorname{var}\left(\mathrm{u}_{2 t}\right)=\sum_{2} \\
X_{t}=\sum_{s=1}^{\infty} E_{3 s} X_{t-s}+\sum_{s=1}^{\infty} F_{3 s} Y_{t-s}+\mathrm{u}_{3 t} & \operatorname{var}\left(\mathrm{u}_{3 t}\right)=\sum_{3} \\
X_{t}=\sum_{s=1}^{\infty} E_{4 s} X_{t-s}+\sum_{s=1}^{\infty} F_{4 s} Y_{t-s}+\mathrm{u}_{4 t} & \operatorname{var}\left(\mathrm{u}_{4 t}\right)=\sum_{4} \\
Y_{t}=\sum_{s=1}^{\infty} G_{1 s} Y_{t-s}+\mathrm{v}_{1 t} & \operatorname{var}\left(\mathrm{v}_{1 t}\right)=\mathrm{T}_{1} \\
Y_{t}=\sum_{s=1}^{\infty} G_{2 s} X_{t-s}+\sum_{s=1}^{\infty} H_{2 s} Y_{t-s}+\mathrm{v}_{2 t} & \operatorname{var}\left(\mathrm{v}_{2 t}\right)=\mathrm{T}_{2} \\
Y_{t}=\sum_{s=1}^{\infty} G_{3 s} X_{t-s}+\sum_{s=1}^{\infty} H_{3 s} Y_{t-s}+\mathrm{v}_{3 t} & \operatorname{var}\left(\mathrm{v}_{3 t}\right)=\mathrm{T}_{3} \\
Y_{t}=\sum_{s=1}^{\infty} G_{4 s} X_{t-s}+\sum_{s=1}^{\infty} H_{4 s} Y_{t-s}+\mathrm{v}_{4 t} & \operatorname{var}\left(\mathrm{v}_{4 t}\right)=\mathrm{T}_{4}
\end{array}
$$

Based on the equation system above, Geweke (1982) [31] defined the measure of linear feedback from $Y$ to $X$ as

$$
F_{Y \rightarrow X}=\ln \left(\left|\Sigma_{1}\right| /\left|\Sigma_{2}\right|\right)
$$

The measure is always non-negative and takes the value of zero only if the linear feedback running from $Y$ to $X$ is absent. Symmetrically, the measure of linear feedback from $X$ to $Y$ is

$$
F_{X \rightarrow Y}=\ln \left(\left|\mathbf{T}_{1}\right| /\left|\mathbf{T}_{2}\right|\right)
$$

and the measure of instantaneous linear feedback is

$$
\left.F_{X \cdot Y}=\ln \left(\left|\mathbf{T}_{1}\right| *\left|\Sigma_{2}\right|\right) /|Y|\right)
$$

where $\mathrm{Y}=\operatorname{var}\left(\begin{array}{l}\mathrm{u}_{2 t} \\ \mathrm{v}_{2 t}\end{array}\right)=\left[\begin{array}{cc}\sum_{2} & \mathrm{C} \\ \mathrm{C}^{\prime} & \mathrm{T}_{2}\end{array}\right]$.

We can decompose the measure of linear dependence between any two groups of time series $X$ and $Y, F_{X, Y}$, as the sum of the measure of linear feedback from the $X$ to $Y, F_{X \rightarrow Y}$, linear feedback from 
the $Y$ to $X, F_{X \rightarrow Y}$, and instantaneous linear feedback between the two series, $F_{X \cdot Y}$, as shown in Equation (1). In the notion of Equations (3)-(10), Geweke (1982) [31] also proves the following equivalence:

$$
\begin{gathered}
F_{X, Y}=\ln \left(\left|\Sigma_{1}\right| /\left|\mathbf{\Sigma}_{4}\right|\right)=\ln \left(\left|\mathbf{T}_{1}\right| /\left|\mathbf{T}_{2}\right|\right) \\
F_{X \rightarrow Y}=\ln \left(\left|\Sigma_{3}\right| /\left|\Sigma_{4}\right|\right)=\ln \left(\left|\mathbf{T}_{1}\right| /\left|\mathbf{T}_{2}\right|\right) \\
F_{Y \rightarrow X}=\ln \left(\left|\Sigma_{1}\right| /\left|\Sigma_{2}\right|\right)=\ln \left(\left|\mathbf{T}_{3}\right| /\left|\mathbf{T}_{4}\right|\right) F_{X \cdot Y}=\ln \left(\left|\Sigma_{2}\right| /\left|\Sigma_{3}\right|\right)=\ln \left(\left|\mathbf{T}_{2}\right| /\left|\mathbf{T}_{3}\right|\right)
\end{gathered}
$$

Based on this equivalence, we can simplify the estimations to Equations (3)-(6) only, and avoid the estimations (7)-(10) which require multivariate vector $y$ as the dependent variables. Note that the error terms in nested estimation Equations (3)-(6) should become smaller as we include more dependent variables. Therefore, we shall expect the ordering of variance as $\Sigma_{1}>\sum_{2}>\sum_{3}>\Sigma_{4}$, which further implies that all the measures are non-negative, and zero only when feedback (causality) of the relevant type is absent.

To ensure the white-noise property, we adopted the approach by Tan and Cheng (1995) [33] and conducted an informal test by running the first-order autoregressive model on the residuals of each equation. Under the null hypothesis that there is no unidirectional causality running from $y$ to $x$, i.e., if $\hat{F}_{Y \rightarrow X}=0$, then $n \hat{F}_{Y \rightarrow X} \sim \chi^{2}(k l p)$.

Similarly, it follows that if $\hat{F}_{X \rightarrow Y}=0, n \hat{F}_{X \rightarrow Y} \sim \chi^{2}(k l p)$ and if $\hat{F}_{X \cdot Y}=0, n \hat{F}_{X \cdot Y} \sim \chi^{2}(k l)$. As these are nested hypotheses, all three restrictions could be tested simultaneously since if $\hat{F}_{X, Y}=0$, then $n \hat{F}_{X, Y} \sim \chi^{2}[k l(2 p+1)]$. Confidence intervals for these measures may also be constructed from ordinary least squares estimates.

\subsection{Data}

The data utilized in the research has been collected from several key sources and is a combination of both hard and survey data. The dependent variable ITA data was collected from the World Bank database [34] and indicates the total amount of international inbound visitors who arrived in Malaysia. The overview of the independent variables proceeds by a description of the individual indicators by environment. We proposed four major environments and respective indicators under certain environments which could affect tourism arrivals in Malaysia, as summarized in Table 1.

The independent variables under the government policy environment (GPE) include government expenditure on tourism (GET) as a percentage of GDP and capital investment on tourism (CI) as a percentage of GDP were both collected from the World Travel and Tourism Council (WTTC). The GET indicator describes the government's spending as a percentage of total GDP spent on T\&T services directly linked to visitors, and CI includes spending by all sectors involved in the T\&T industry (World Travel \& Tourism Council, 2014 [8]).

Table 1. Variables Used in Empirical Analysis.

\begin{tabular}{cc}
\hline Environment & Indicator \\
\hline Environmental and Infrastructure Environment & Airport Facilities; Air Quality; Internet Users \\
\hline Purchasing Power Environment & Exchange Rate; Consumer Price Index \\
\hline Government Policy Environment & $\begin{array}{c}\text { Government Expenditure on Tourism (\% of GDP); } \\
\text { Capital Investment on Tourism (\% of GDP) }\end{array}$ \\
\hline Safety and Security Environment & Public Security and Safety; Religious Unrest \\
\hline
\end{tabular}

The variables under the environmental and infrastructure environment (EIE) include Airport facilities (AF), Air Quality (AQ) and Internet Users (IU). The explanatory variable AF was obtained from the World Economic Forum's (WEF) Global Competitiveness Index's survey data which asked the respondents to rate the quality of the country's air transportation infrastructure with $1=$ extremely 
underdeveloped and $7=$ extensive and efficient by international standards and was utilized to examine the quality of travel infrastructure. The data on AQ was obtained from the Global Market Information Database (GMID) [35] and examines the amount of fine particulates, micrograms per cubic meter, that are in the air which are capable of causing health damage; AQ in the analysis represents the quality of Malaysia's environment. The final indicator in this environment IU describes the amount of Internet users, individual with access to the Internet, per 100 people and was collected from the World Bank's data set.

The independent variables considered under the purchasing power environment (PPE) include both Exchange Rate (ER) and Consumer Price Index (CPI). The ER data was collected from the International Monetary Fund (IMF) Economic Outlook Database [36], and is the Malaysian Ringgit (MYR) per United States Dollar (USD) average. The CPI data was collected from the World Bank's data set and the indicator describes the changes in the cost to the average consumer of purchasing a specific basket of goods and services on a yearly basis.

The security environment (SE) consists of two independent variables, Public Security and Safety (PSS) and Religious Unrest (RU); both the PSS and RU indicators were collected from the WEF's Global Competitiveness Index and are survey data. The PSS indicator is a composite of two survey questions combined to access the state of security and safety in the country; the first question asked to what extent does organized crime imposes costs on businesses in the country with $1=$ to a great extent and $7=$ not at all, and the second question asked to what extent can police services be relied upon to enforce law and order with $1=$ cannot be relied upon and 7 = can be completely relied upon (World Economic Forum, 2014 [37]). The indicator RU asked respondents to what extent does the threat of terrorism impose costs on businesses in the country with $1=$ to a great extent and $7=$ not at all (World Economic Forum, 2014 [37]).

All variables used in empirical estimations were subjected to stationary tests. We found variables including international tourist arrivals, capital investments on tourism, consumer price index, government expenditures on tourism to have unit roots at levels. Considering that rendering them stationary is a pre-condition to apply Geweke estimation, we transformed these variables into stationary series before using them in the causality analysis.

The sample of our study spans from 2000 to 2012, and due to limited observations for the period of 2000-2012, we converted the yearly data into quarterly data using quadratic-sum/average method. The intuition behind the quadratic match-sum method is that it fits a local polynomial for each observation of the original (annual) series, using the fitted polynomial to fill in all observations of the higher frequency (quarterly) series associated with the period. The sum of the interpolated quarterly data points should match the actual annual data points.

\section{Empirical Results}

As discussed in the previous section, we employ a Geweke causality analysis in this paper to identify the causal determinants of the growth of T\&T in Malaysia. Before we undertake a causality test, we utilize a stepwise regression in order to narrow down the "best" set of explanatory variables among the list of 9 variables we identified earlier.

Table 2 presents the results of the stepwise regression. Among the 9 afore-mentioned candidates for explanatory variables, government expenditure on tourism (percent of GDP); capital investment on tourism (percent of GDP); airport facilities and religious unrest appear to become the most significant variables which can be used for our causality analysis. 
Table 2. Summary of linear stepwise regression analysis on tourism development in Malaysia.

\begin{tabular}{|c|c|c|c|c|}
\hline $\begin{array}{c}\text { Dependent } \\
\text { Variable: } \\
\text { International } \\
\text { tourism arrivals }\end{array}$ & & $+\sum_{k=1}^{K} \beta_{k} x_{i k}+\epsilon_{i}$ & & $\begin{array}{c}\text { Number of obs }=51 \\
F=6.84 \\
\text { Prob }>F=0.0002 \\
\text { Adjusted } R^{2}=0.3186\end{array}$ \\
\hline $\begin{array}{c}\text { Independent } \\
\text { Variables }\end{array}$ & $\beta$ & Standard error & $\begin{array}{c}t \\
\text { statistics }\end{array}$ & $p$-Value \\
\hline Airport facilities & $-757,593.2^{* * *}$ & $211,494.7$ & -3.58 & 0.001 \\
\hline $\begin{array}{c}\text { Capital investment } \\
\text { on tourism }(\% \text { of } \\
\text { GDP) }\end{array}$ & $75,256.91^{* * *}$ & $19,438.2$ & 3.87 & 0.000 \\
\hline $\begin{array}{c}\text { Government } \\
\text { expenditure on } \\
\text { tourism }(\% \text { of GDP) }\end{array}$ & $1,295,848^{* *}$ & $490,886.8$ & 2.64 & 0.011 \\
\hline Religious unrest & $283,919.4^{* * *}$ & $99,380.75$ & 2.86 & 0.006 \\
\hline Constant & $215,294.6$ & $1,419,340$ & 0.15 & 0.880 \\
\hline
\end{tabular}

As can be inferred from the bidirectional causality results shown in Table $3^{1}$, there exists a significant bidirectional association between ITA and GET at the 1 percent level of significance and the total causality is primarily made up of the instantaneous association. In examining the relationship between ITA and AF, there is evidence of not only a strong bidirectional association between the dependent and explanatory variable at the 1 percent level of significance, but also strong feedback from AF to ITA at the 1 percent level of significance. While there is a significant bidirectional association between the ITA and AF, the feedback from AF to ITA underlines the important role that AF can have in contributing to increased ITA. In the case of ITA and RU, the results highlight that there is a bidirectional association between ITA and RU at the 1 percent level of significance, and a weak feedback from RU to ITA at the 10 percent level of significance. The bidirectional association between ITA and CI is not significant.

1 For the subsequent Geweke causality tables, figures of $F_{x, y}$ may not be equal to the sum of figures of $F_{x \rightarrow y}, F_{y \rightarrow x}$ and $F_{x \cdot y}$ due to round-up. 
Table 3. Estimated measures of bidirectional feedback between International Tourism Arrivals (ITA), Capital Investment on Tourism (\% of GDP) (CI), Government Expenditure on Tourism (\% of GDP) (GET), Airport Facilities (AF) and Religious Unrest (RU) for Malaysia, 2000-2012. ${ }^{a, b}$

\begin{tabular}{|c|c|c|c|c|c|}
\hline \multicolumn{2}{|c|}{ Economic Aggregates } & \multicolumn{4}{|c|}{$\boldsymbol{H}_{0}\left(\boldsymbol{F}_{\boldsymbol{X}, \boldsymbol{Y}}=\boldsymbol{F}_{\boldsymbol{X} \rightarrow \boldsymbol{Y}}+\boldsymbol{F}_{\boldsymbol{Y} \rightarrow \boldsymbol{X}}+\boldsymbol{F}_{\boldsymbol{X} \cdot \boldsymbol{Y}}\right)$} \\
\hline$X$ & $Y$ & $F_{X, Y}$ & $F_{X \rightarrow Y}$ & $F_{Y \rightarrow X}$ & $F_{X \cdot Y}$ \\
\hline ITA & $\mathrm{CI}$ & $\begin{array}{c}0.0407 \\
(0.8611)\end{array}$ & $\begin{array}{c}0.0095 \\
(0.8009)\end{array}$ & $\begin{array}{c}0.0284 \\
(0.5131)\end{array}$ & $\begin{array}{c}0.0028 \\
(0.7146)\end{array}$ \\
\hline $\mathrm{CI}$ & ITA & $\begin{array}{c}0.0167 \\
(0.9779)\end{array}$ & $\begin{array}{c}0.0053 \\
(0.8827)\end{array}$ & $\begin{array}{c}0.0086 \\
(0.8173)\end{array}$ & $\begin{array}{c}0.0028 \\
(0.7146)\end{array}$ \\
\hline ITA & GET & $\begin{array}{c}0.5846^{* * *} \\
(0.0000)\end{array}$ & $\begin{array}{c}0.0407 \\
(0.1578)\end{array}$ & $\begin{array}{c}0.0069 \\
(0.5616)\end{array}$ & $\begin{array}{c}0.5370^{* * *} \\
(0.0000)\end{array}$ \\
\hline GET & ITA & $\begin{array}{c}0.5938^{* * *} \\
(0.0000)\end{array}$ & $\begin{array}{c}0.0379 \\
(0.1730)\end{array}$ & $\begin{array}{c}0.0190 \\
(0.3350)\end{array}$ & $\begin{array}{c}0.5370^{* * *} \\
(0.0000)\end{array}$ \\
\hline ITA & $\mathrm{AF}$ & $\begin{array}{l}1.4886^{* * *} \\
(0.0000)\end{array}$ & $\begin{array}{c}0.0010 \\
(0.9765)\end{array}$ & $\begin{array}{c}0.3063^{* * *} \\
(0.0007)\end{array}$ & $\begin{array}{l}1.1813^{* * *} \\
(0.0000)\end{array}$ \\
\hline $\mathrm{AF}$ & ITA & $\begin{array}{c}1.3966^{* * *} \\
(0.0000)\end{array}$ & $\begin{array}{c}0.1245^{*} \\
(0.0536)\end{array}$ & $\begin{array}{c}0.0908 \\
(0.1184)\end{array}$ & $\begin{array}{c}1.1813^{* * *} \\
(0.0000)\end{array}$ \\
\hline ITA & RU & $\begin{array}{c}0.7741^{* * *} \\
(0.0000)\end{array}$ & $\begin{array}{c}0.0031 \\
(0.9301)\end{array}$ & $\begin{array}{c}0.1300^{*} \\
(0.0472)\end{array}$ & $\begin{array}{c}0.6410^{* * *} \\
(0.0000)\end{array}$ \\
\hline RU & ITA & $\begin{array}{c}0.6983^{* * *} \\
(0.0000)\end{array}$ & $\begin{array}{c}0.0081 \\
(0.8272)\end{array}$ & $\begin{array}{c}0.0492 \\
(0.3148)\end{array}$ & $\begin{array}{l}0.6410^{* * *} \\
(0.0000)\end{array}$ \\
\hline
\end{tabular}

$\mathrm{a} *$ and ${ }^{* * *}$ denote $10 \%$ and $1 \%$ level of significance, respectively; ${ }^{b}$ confidence interval can be provided upon request.

Analyzing the results in Table 4 of the multivariate causality between ITA on the $X$ vector, and GET, CI, AF and RU on the $Y$ vector highlights that there is a strong association between $X$ and $Y$ at the 1 percent level of significance, and linear feedback from $Y$ to $X$ at the 5 percent level of significance, and instantaneous association at 1 percent level of significance. The results indicate the role the explanatory variables can jointly and simultaneously have in contributing to an increase in ITA in Malaysia.

Table 4. Estimated measures of multi-directional feedback between International Tourism Arrivals (ITA), Capital Investment on Tourism (\% of GDP) (CI), Government Expenditure on Tourism (\% of GDP) (GET), Airport Facilities (AF) and Religious Unrest (RU) for Malaysia, 2000-2012. a,b

\begin{tabular}{cccccc}
\hline \multicolumn{2}{c}{ Economic Aggregates } & \multicolumn{4}{c}{$\boldsymbol{H}_{0}\left(\boldsymbol{F}_{\boldsymbol{X}, \boldsymbol{Y}}=\boldsymbol{F}_{\boldsymbol{X} \rightarrow \boldsymbol{Y}}+\boldsymbol{F}_{\boldsymbol{Y} \rightarrow \boldsymbol{X}}+\boldsymbol{F}_{\boldsymbol{X} \cdot \boldsymbol{Y}}\right)$} \\
\hline $\boldsymbol{X}$ & $\boldsymbol{Y}$ & $\boldsymbol{F}_{\boldsymbol{X}, \boldsymbol{Y}}$ & $\boldsymbol{F}_{\boldsymbol{X} \rightarrow \boldsymbol{Y}}$ & $\boldsymbol{F}_{\boldsymbol{Y} \rightarrow \boldsymbol{X}}$ & $\boldsymbol{F}_{\boldsymbol{X} \cdot \boldsymbol{Y}}$ \\
\hline \multirow{4}{*}{$\mathrm{ITA}$} & $\mathrm{CI}$ & & & & \\
& $\mathrm{GET}$ & $2.2707^{* * *}$ & 0.2604 & $0.4086^{* *}$ & $1.6017^{* * * *}$ \\
& AF & $(0.0000)$ & $(0.1409)$ & $(0.0138)$ & $(0.0000)$ \\
& RU & & & &
\end{tabular}

a $* *$ and $\overline{* * *}$ denote $5 \%$ and $1 \%$ level of significance, respectively; ${ }^{b}$ confidence interval would be provided upon request.

Using factor analysis, we constructed four environments-(1) environmental and infrastructure, (2) purchasing power, (3) government policy, and (4) safety and security-to bolster the previous results in order to analyze the relationship between the specific policy environments and the dependent 
variable of interest, ${ }^{2}$ a description of the variables considered in each environment were discussed earlier.

As the results in Table 5 highlight, there is a strong bidirectional association between ITA and GPE at the 1 percent level of significance, as well as a strong bidirectional association between ITA and SE at the 1 percent level of significance. Interestingly, in examining the relationship between ITA and PPE, the relationship between the two is not significant. Additionally, EIE was dropped from the bivariate and multivariate tests, as the environment bidirectional causality did not pass the white-noise test.

Table 5. Estimated measures of bidirectional feedback between International Tourism Arrivals (ITA), Purchasing Power Environment (PPE) and Government Policy Environment (GPE) and Safety and Security Environment (SSE) for Malaysia, 2000-2012. ${ }^{\text {a,b }} 3$

\begin{tabular}{|c|c|c|c|c|c|}
\hline \multicolumn{2}{|c|}{ Economic Aggregates } & \multicolumn{4}{|c|}{$H_{0}\left(F_{X, Y}=F_{X \rightarrow Y}+F_{Y \rightarrow X}+F_{X \cdot Y}\right)$} \\
\hline$X$ & $Y$ & $F_{X, Y}$ & $F_{X \rightarrow Y}$ & $F_{Y \rightarrow X}$ & $F_{X \cdot Y}$ \\
\hline ITA & PPE & $\begin{array}{c}0.0208 \\
(0.7972)\end{array}$ & $\begin{array}{c}0.0036 \\
(0.6747)\end{array}$ & $\begin{array}{c}0.0001 \\
(0.9421)\end{array}$ & $\begin{array}{c}0.0171 \\
(0.3607)\end{array}$ \\
\hline PPE & ITA & $\begin{array}{c}0.0254 \\
(0.7421)\end{array}$ & $\begin{array}{c}0.0005 \\
(0.8703)\end{array}$ & $\begin{array}{c}0.0078 \\
(0.5357)\end{array}$ & $\begin{array}{c}0.0171 \\
(0.3607)\end{array}$ \\
\hline ITA & GPE & $\begin{array}{c}0.5846^{* * *} \\
(0.0000)\end{array}$ & $\begin{array}{c}0.0407 \\
(0.1578)\end{array}$ & $\begin{array}{c}0.0069 \\
(0.5616)\end{array}$ & $\begin{array}{c}0.5370^{* * *} \\
(0.0000)\end{array}$ \\
\hline GPE & ITA & $\begin{array}{c}0.5938^{* * *} \\
(0.0007)\end{array}$ & $\begin{array}{c}0.0379 \\
(0.1730)\end{array}$ & $\begin{array}{c}0.0190 \\
(0.3350)\end{array}$ & $\begin{array}{c}0.5370^{* * *} \\
(0.0000)\end{array}$ \\
\hline ITA & SSE & $\begin{array}{c}0.8878^{* * *} \\
(0.0000)\end{array}$ & $\begin{array}{c}0.0082 \\
(0.8244)\end{array}$ & $\begin{array}{c}0.0893 \\
(0.1227)\end{array}$ & $\begin{array}{c}0.7904^{* * *} \\
(0.0000)\end{array}$ \\
\hline SSE & ITA & $\begin{array}{c}0.8394^{* * *} \\
(0.0000)\end{array}$ & $\begin{array}{c}0.0039 \\
(0.9117)\end{array}$ & $\begin{array}{c}0.0451 \\
(0.3466)\end{array}$ & $\begin{array}{c}0.7904^{* * *} \\
(0.0000)\end{array}$ \\
\hline
\end{tabular}

a *** denotes $1 \%$ level of significance; ${ }^{b}$ confidence interval can be provided upon request.

Proceeding to the Geweke multidirectional causality in Table 6, in which GPE, SE and PPE were collated on the $Y$ vector and ITA on the $X$ vector, we find that there exists a strong association between the $X$ and $Y$ at the 1 percent level of significance. Furthermore, the instantaneous association between $X$ and $Y$ are significant at 1 percent and contribute the majority of the total causality.

Table 6. Estimated measures of multi-directional feedback between International Tourism Arrivals (ITA), Purchasing Power Environment (PPE), Government Policy Environment (GPE) and Safety and Security Environment (SSE) for Malaysia, 2000-2012. a,b

\begin{tabular}{cccccc}
\hline \multicolumn{2}{c}{ Economic Aggregates } & \multicolumn{4}{c}{$\boldsymbol{H}_{0}\left(\boldsymbol{F}_{\boldsymbol{X}, \boldsymbol{Y}}=\boldsymbol{F}_{\boldsymbol{X} \rightarrow \boldsymbol{Y}}+\boldsymbol{F}_{\boldsymbol{Y} \rightarrow \boldsymbol{X}}+\boldsymbol{F}_{\boldsymbol{X} \cdot \boldsymbol{Y}}\right)$} \\
\hline $\boldsymbol{3}$ & $\boldsymbol{Y}$ & $\boldsymbol{F}_{\boldsymbol{X}, \boldsymbol{Y}}$ & $\boldsymbol{F}_{\boldsymbol{X} \rightarrow \boldsymbol{Y}}$ & $\boldsymbol{F}_{\boldsymbol{Y} \rightarrow \boldsymbol{X}}$ & $\boldsymbol{F}_{\boldsymbol{X} \cdot \boldsymbol{Y}}$ \\
\hline \multirow{2}{*}{ ITA } & PPE & $1.0921^{* * *}$ & 0.0588 & 0.2092 & $0.8241^{* * *}$ \\
& GPE & $(0.0000)$ & $(0.8378)$ & $(0.1319)$ & $(0.0000)$ \\
\hline
\end{tabular}

a *** denotes $1 \%$ level of significance; ${ }^{\mathrm{b}}$ confidence interval can be provided upon request.

To summarize, the Geweke causality results suggest that Malaysia's government expenditures on tourism promotions as well as infrastructure investments such as on enhancing airports facilities emerge as causal and significant determinants of the growth in the T\&T industry.

2 For the subsequent Geweke causality tables, figures of $F_{x, y}$ may not be equal to the sum of figures of $F_{x \rightarrow y}, F_{y \rightarrow x}$ and $F_{x \cdot y}$ due to round-up. 


\section{Conclusions and Policy Implications}

This paper has tried to empirically understand the causal factors driving the growth of international tourist arrivals in Malaysia, using a Geweke causality framework. The findings of the paper leave us with important policy insights that could serve as useful guidance to policymakers to boost the capacity and enhance the quality of the country's domestic T\&T industry.

Specifically, our results show that there exists a strong causal link between airport facilities and international tourist arrivals, with airport facilities significantly driving the growth of international tourist arrivals. This result highlights the prominent role that the quality of air transportation facilities can have on contributing to the growth of the T\&T industry into Malaysia.

Through a review of the government policies embodied in both the NEM and 10th Malaysia Plan, it is evident that the government has realized not only the importance of the industry as a whole, but also the need to improve the infrastructure handling international visitors for both business and leisure. In the NEM, two of the policy prescriptions advocated were to further prioritize air and port infrastructure, and improve the tourism services to ensure seamless and quality services along the T\&T value chain (National Economic Advisory Council, 2010 [11,12]). As the government plans have highlighted, these policy initiatives can have beneficial spillovers that can enhance the quality of the domestic T\&T industry as well as its capacity to handle international trade and logistics.

As demonstrated by the empirical results, government policies can have a substantial effect on international tourist arrivals into Malaysia; both government expenditures on tourism and the government policy environment had a significant bidirectional association with international tourist arrivals at the 1 percent level of significance.

In the 10th Malaysia Plan, the government has outlined several key policy initiatives that require investment from both the public and private sector; these include, but are not limited to, expanding the presence and promotional activities of Tourism Malaysia offices, the creation of new tourism clusters for both Eastern and Western Malaysia that seeks to attract visitors to both the heritage and ecological attractions, and developing new products such as the Malaysia Truly Asia Center in Kuala Lumpur (Prime Minister's Department Economic Planning Unit, 2010 [13]). While the empirical results confirm the important role of government expenditure on the T\&T industry, additional resources from both the public and private sector should be utilized to bolster T\&T services and attractions.

Additionally, as is evident in the empirical results, there is also a significant association between international tourist arrivals and the security environment at the 1 percent level of significance; Furthermore, we also find a bidirectional association between religious unrest and international tourist arrivals at the 1 percent level of significance while there is a weak reverse feedback from religious unrest to international tourist arrivals at the 10 percent level of significance. These results indicate that the country's safety and security environment is an important determinant of growth in tourist arrivals and points out the need for the government to ensure a safe and secure environment. In order to ensure the safety of the local populace and international visitors, it is important that Malaysia continues to invest in the police force and strengthen its law and order.

Author Contributions: Tan Khee Giap was responsible for conceptualizing the paper, framing its research objectives, identifying a suitable empirical methodology and ensuring overall quality control of the paper. Sasidaran Gopalan was responsible mainly for the write-up of the paper at various stages and the subsequent follow-through of the paper with the journal. Ye Ye was mainly responsible for the data collection and background analysis in addition to doing the literature review and executing the empirical analysis.

Conflicts of Interest: The authors declare no conflict of interest.

\section{References}

1. Gopalan, S. Mapping India-EU Tourism Flows; CARIM-India Research Report No. 2013/15; Robert Schuman Centre for Advanced Studies, European University Institute: San Domenico di Fiesole (FI), Italy, 2013. 
2. United Nations Conference on Trade and Development (UNCTAD). Sustainable Tourism: Contribution to Economic Growth and Sustainable Development. In Proceedings of the Expert Meeting on Tourism's Contribution to Sustainable Development, Geneva, Switzerland, 14-15 March 2013.

3. Overseas Development Institute. Can Tourism Offer Pro-Poor Pathways to Prosperity? 2007. Available online: http://www.odi.org/sites/odi.org.uk/files/odi-assets/publications-opinion-files/110.pdf (accessed on 20 February 2016).

4. Ashley, C.; De Brine, P.; Lehr, A.; Wilde, H. The Role of Tourism Sector in Expanding Economic Opportunity; Corporate Social Responsibility Initiative Report No. 23; Kennedy School of Government, Harvard University: Cambridge, MA, USA, 2007.

5. United Nations World Tourism Organization (UNWTO). UNWTO Tourism Highlights, 2015 ed.; UNWTO, United Nations: Madrid, Spain, 2015.

6. World Travel \& Tourism Council (WTTC). Travel \& Tourism: Economic Impact 2015 Malaysia. Available online: https://www.wttc.org/-/media/files/reports/economic\%20impact\%20research/countries\%202015/ malaysia2015.pdf (accessed on 21 February 2016).

7. World Travel \& Tourism Council. WTTC Economic Data Search Tool. Available online: http://www. wttc.org/focus/research-for-action/economic-data-search-tool/ (accessed on 22 October 2014).

8. World Travel \& Tourism Council. Travel \& Tourism Economic Impact 2014 Malaysia. Available online: http: / / www.wttc.org/-/media/files/reports/economic\%20impact\%20research/country\%20reports/malaysia2014. pdf (accessed on 14 December 2014).

9. Malik, S.; Chaudhry, I.S.; Sheikh, M.R. Tourism, Economic Growth and Current Account Deficit in Pakistan: Evidence from Co-integration and Causal Analysis. Eur. J. Econ. Finance Adm. Sci. 2010, 22, 21-31.

10. Thano, R. The Impact of Tourism on the Balance of Payments. Am. J. Econ. Finance Manag. 2015, 1, 529-536.

11. National Economic Advisory Council. New Economic Model for Malaysia Part 1. 2010. Available online: http://www.epu.gov.my/epu-theme/pdf/nem.pdf (accessed on 20 February 2016).

12. National Economic Advisory Council. New Economic Model for Malaysia Concluding Part. 2010. Available online: https://www.pmo.gov.my/dokumenattached/NEM_Concluding_Part.pdf (accessed on 15 October 2014).

13. Prime Minister's Department Economic Planning Unit. Tenth Malaysia Plan. 2010. Available online: http://onlineapps.epu.gov.my/rmke10/rmke10_english.html (accessed on 3 October 2014).

14. Tourism Industry Should Promote Malaysia's Selling Points, Stress on Value for Money, Says Najib. The Rakyat Post, 27 August 2015.

15. Mosbah, A.; Al Khuja, M.S.A. A Review of Tourism Development in Malaysia. Eur. J. Bus. Manag. 2014, 6, $1-9$.

16. Nanthakumar, L.; Ibrahim, Y.; Harun, M. Tourism Development Policy, Strategic Alliances and Impact of Consumer Price Index on Tourist Arrivals: The Case of Malaysia. MPRA Paper No. 25376. 2007. Available online: https:/ /mpra.ub.uni-muenchen.de/25376/1/MPRA_paper_25376.pdf (accessed on 20 February 2016).

17. Ministry of Tourism (MoT). Malaysia Country Report. In Proceedings of the 25th CAP-CSA and UNWTO Conference on Sustainable Tourism Development, Hyderabad, India, 12-14 April 2013.

18. Crouch, G.I. The Study of International Tourism Demand: A Survey of Practice. J. Travel Res. 1994, 32, 41-55. [CrossRef]

19. Lim, C. Review of International Tourism Demand Models. Ann. Tour. Res. 1997, 24, 835-849. [CrossRef]

20. Sheldon, P.J. Forecasting Tourism: Expenditures versus Arrivals. J. Travel Res. 1993, 32, 13-20. [CrossRef]

21. Uysal, M.; Crompton, J.L. Determinants of Demand for International Tourist Flows to Turkey. Tour. Manag. 1984, 5, 288-297. [CrossRef]

22. Onder, A.O.; Candemir, A.; Kumrai, N. An Empirical Analysis of the Determinants of International Tourism Demand: The Case of Izmir. Eur. Plan. Stud. 2009, 17, 1525-1533. [CrossRef]

23. Song, H.; Wong, K.F.; Chon, K.K. Modeling and Forecasting the Demand for Hong Kong Tourism. Hosp. Manag. 2003, 22, 435-451. [CrossRef]

24. Culiuc, A. Determinants of International Tourism; IMF Working Paper No. WP/14/82; International Monetary Fund: Washington, DC, USA, 2014.

25. Prideaux, B. Factors Affecting Bilateral Tourism Flows. Ann. Tour. Res. 2005, 32, 780-801. [CrossRef]

26. Gujarati, D. Basic Econometrics, 4th ed.; McGraw-Hill: New York, NY, USA, 2004. 
27. Pett, M.A.; Lackey, N.R.; Sullivan, J. Making Sense of Factor Analysis; Sage Publications: Thousand Oaks, CA, USA, 2003.

28. Granger, C.W.J. Economic Processes Involving Feedback. Inf. Control 1963, 6, 28-48. [CrossRef]

29. Granger, C.W.J. Investigating Causal Relations by Econometric Models and Cross-spectral Methods. Econometrica 1969, 37, 424-438. [CrossRef]

30. Sims, C. Money, Income, and Causality. Am. Econ. Rev. 1972, 62, 540-552.

31. Geweke, J. Measurement of Linear Dependence and Feedback between Multiple Time Series. J. Am. Stat. Assoc. 1982, 77, 304-313. [CrossRef]

32. Calderón, C.; Liu, L. The direction of causality between financial development and economic growth. J. Dev. Econ. 2003, 72, 321-334. [CrossRef]

33. Tan, K.G.; Cheng, C.S. The Causal Nexus of Money, Output and Prices in Malaysia. Appl. Econ. 2006, 27, 1245-1251.

34. The World Bank Data. Available online: http://data.worldbank.org (accessed on 22 October 2014).

35. Global Market Information Database (GMID). Available online: http://libportal.nus.edu.sg/frontend/ databases-view?DBsearchString=GMID (accessed on 5 July 2014).

36. International Monetary Fund. International Monetary Fund Economic Outlook Database. Available online: http:/ / www.imf.org/external/ns/cs.aspx?id=28 (accessed on 5 July 2014).

37. World Economic Forum. World Economic Forum Global Competitiveness Index. Available online: http:// www.weforum.org/issues/competitiveness-0/gci2012-data-platform/ (accessed on 5 May 2014).

(C) 2016 by the authors; licensee MDPI, Basel, Switzerland. This article is an open access article distributed under the terms and conditions of the Creative Commons by Attribution (CC-BY) license (http:/ / creativecommons.org/licenses/by/4.0/). 